\title{
Analysis: The new evaluation standard for Green Building in China
}

\author{
Jixue Zou Jing Dong \\ College of architectural engineering, Xi'an Eurasia University, Xi'an Shaanxi,China 710065
}

Keywords: Green architecture; revision content; comparative analysis

Abstract.Green energy-saving building is the inevitable trend of the sustainable development of the construction industry, green building evaluation standard system of green building development to an important role. In this paper, the Chinese version of the green building evaluation criteria GB/T50378-2014 and GB/T50378-2006.

\section{Research background}

Green building, refers to the building's full life cycle to maximize resource conservation (energy, land, water, and materials) to protect the environment and reduce pollution, provide people with healthy, appropriate and efficient use of space, and harmonious society construction. Circular in early 2013, the national development and Reform Commission and the Ministry of housing and in the program of action of the green building, explicitly put forward the "Twelve-Five" period, complete the new green building 1 billion square meters, by the end of 2015, 20\% of new town construction achieve the goal of green building standards. Implementation of the new evaluation standard for green building conforms to the needs of the development of green architecture in China, to promote green building development, will play an important role in promoting the construction of ecological civilization.

Recently, the State Department of housing and urban-rural construction announcement, approval of the evaluation standard for green building standards, the number is GB/T50378-2014, and since January 1, 2015. The GB/T50378-2006 abrogated the evaluation standard for green building. This standard by the Ministry of housing and construction industry, China Research Institute of standards and norms of the Department Organization publishing.

Main technical contents GB/T50378-2014 of the green building assessment standard is divided into 11 chapters, main technical elements are: General principles, terminology, basic provisions, section with an outdoor environment, energy-saving and energy and water conservation and utilization of water resources, raw materials and the use of material resources, indoor environmental quality, construction management, operations management, improvement and innovation. Its original focus GB/T50378-2006 revision of the evaluation standard for green building includes

Appropriate Building Types GB/T50378-2014 the scope of the evaluation standard for green building, the original GB/T50378-2006 the evaluation standard for green building in the residential construction of office buildings, shopping malls and public buildings construction and hotel construction, was further extended to the major types of civil buildings. The basis for the determination of which is

Green building evaluation practice in recent years, enrich the connotation and extension of green architecture, industry, building the category needs of practicing green ideas put forward. By the end of 2012, 742 in green building project has 5 health class, Convention and exhibition, 9, school education classes on 12, but the specific evaluation reflects the original GB/T50378-2006 of the 
green building assessment standard for these types of buildings considered enough.

In recent years has project has green office building evaluation standard GB/T50908-2013, and green store building evaluation standard (has approval), and Green Hotel building evaluation standard, and green hospital building evaluation standard, and Green Expo building evaluation standard, for specific building type of green building evaluation standard, green building evaluation standard GB/T50378-2014 on including above building type zainei of various civil be and Manpower consider, Will contribute to the coordination between the different national standards, form a unified green building evaluation system.

Comments on the work of the project also included 4 health classes, 5 Conference and exhibition classes, 7 classes for schools and terminals, logistics centers and other buildings, validated the evaluation standard for green building GB/T50378-2014 for this application.

Evaluation Stages Differentiation The GB/T50378-2006 requirements of the evaluation standard for green building evaluation should be carried out in the building put into use a year later. But later issued detailed rules for the implementation of the green building assessment identifies the (trial revision) (IBR fully [2008]61), clearly identifies the green building assessment into "green building assessment identifies" (planning, design or construction stage, valid for 2 years) and "green building assessment identifies" (has been completed and put into use, valid for 3 years). And, after years of practice, proves the feasibility of this phased evaluation, as well as the active role of promoting green building in China. Therefore, GB/T50378-2014 the evaluation standard for green building Division were also made in the evaluation phase, allows for better use with the related governance documents.

Specific methods, according to the results of the public consultation and feedback with $66.3 \%$ agreed that the words "construction management", "operational" evaluation of two chapters only at run time. Based on this, GB/T50378-2014 will the evaluation standard for green building design elements as "section with an outdoor environment", "energy-saving and energy use", "water conservation and use of water resources", "materials and material resource utilization", "indoor environmental quality," Chapter 5, evaluation is based on the increasing "construction management", "operations management" Chapter 2

Evaluation Index System Index big class aspects, in original green building evaluation standard GB/T50378-2006 in the section to and outdoor environment, and energy-saving and energy using, and water and water resources using, and section material and material resources using, and indoor environment quality and operation management 6 big class index of based Shang, green building evaluation standard GB/T50378-2014 increased has "construction management", better to achieved on building full life period of cover.

Specific index (evaluation provisions) aspects, according to early the aspects of research results, and sought views and project try assessment two aspects work by feedback of situation, to standard amendment before and after reached the evaluation grade of difficult easy degree slightly has improve and as makes the star green building identifies project number is pyramid shaped distribution for starting point, through added refinement, and cut simplified, and modified content or index value, and added, and canceled, and split points, and merged, and adjustment chapters location or index property, way further perfect has evaluation index system (summary Yu table 1 ) (2014 16 the construction science and technology magazine).

Evaluation and grading method According to the original GB/T50378-2006 of the green building assessment standard revisions and recommendations, amend the Group at its first meeting 
determine the quantitative evaluation methods. After repeated studies and discussions of the green building assessment standard of the GB/T50378-2014 method to calculate the indicators separately one by one after scoring score points and additional points, and then to all kinds of indicators weighted scoring and added additional score calculated on the total score. Grades were based on the "triple control" approach: the first is still consistent with the original GB/T50378-2006 of the green building assessment standard, to maintain a certain amount of control, as the basic requirements for green building second fixed minimum score requirement in each index; Finally, specific grading according to the total score.

Strictly speaking, these "indicator" and "total score" is actually "score". Architectural diversity, various types of indicators under the evaluation provisions could not be applied to all of the buildings, to a specific comment on building, there are evaluation provisions cannot be nominated. Therefore, the "score" to measure the building actually achieved the level is more reasonable. But in practice, "according to the classification" are more likely to be understood and accepted, GB/T50378-2014 the evaluation standard for green building in the "basic provisions" chapter provides a method for converting, avoid the emergence on the face of "scoring"

\section{Conclusions}

Construction activity is one of greatest impact on natural resources, the environment of human activities, and developing green building in the development process should be implemented to save resources and protect the environment of the national policy on technical, economic, strict enforcement of the national policy on technical, economic, strict implementation of the new evaluation standard for green building GB/T50378-2014, building a resource-conserving, environment-friendly and energy conservation and emission reduction to prepare.

\section{References}

[1] Sen Ye. Comparative study on Evaluation System of green building -- a case study of ESGB and CASBEE in Japan [D] Kunming: Kunming University of Science and Technology, 2011

[2] GB/T50378-2014. Green building evaluation standard "S"

[3] Ministry of housing and Urban Rural Development Center for science and technology development. Green building evaluation guide [M]. Beijing: China Building Industry Press, 2010 